\title{
As leituras do cotidiano: os memes nas aulas de Língua Portuguesa - linguagens e seus códigos
}

\author{
Daily readings: memes in Portuguese Language classes - languages and their codes \\ Lectura diaria: memes en las clases de Portugués - idiomas y sus códigos
}

Recebido: 17/08/2021 | Revisado: 22/08/2021 | Aceito: 25/08/2021 | Publicado: 27/08/2021

Carolina Tenuta Portela

ORCID: https://orcid.org/0000-0002-4821-1494 Universidade de Cuiabá, Brasil

E-mail: cportela18@gmail.com

Lucy Ferreira Azevedo

ORCID: https://orcid.org/0000-0002-7072-3859

Universidade de Cuiabá, Brasil

E-mail: lucyfazevedo@gmail.com

\begin{abstract}
Resumo
Analisar os memes e a língua verbal e não verbal no dia-a-dia das aulas de língua portuguesa representa construir algumas reflexões para apreciação e abrangência das materialidades discursivas dos memes dentro da conjuntura escolar. Com o advento da era digital, muitos conteúdos são espalhados a todo tempo, inclusive os memes. Surgem, portanto, várias hipóteses e, entre elas, se a linguagem verbal e não verbal dentro das aulas de língua portuguesa, por meio da análise de memes, promoveria a aprendizagem na Escola Básica. Diante da proposição, traçou-se o objetivo fundamental do estudo que é analisar o eixo Linguagens e seus códigos por meio da apreciação de memes no contexto do dia-a-dia das aulas de língua portuguesa. Pretende-se, em estudo de caso de natureza analítica, ler e selecionar alguns textos, seguindo os critérios: atualidade, proposta gráfica original e inteligente, serventia social e a julgamento abordado com criatividade. Os corpora serão textos difundidos tecnologicamente para a descrição e explanação para um trabalho mais ativo na escola que no momento carece de apoio para novas propostas advindas de caminhos além dos livros e apostilas. Os teóricos basilares serão: Bronckart (2005); Kleiman (2007); Xavier (2002); Soares (2004) e a BNCC (2016), entre outros autores. Acredita-se que a linguagem verbal e não verbal dentro do contexto do cotidiano das aulas de língua portuguesa poderá conduzir os estudantes à percepção de diferentes semioses propostas pelas linguagens possibilitadas pela tecnologia/WEB.
\end{abstract}

Palavras-chave: Linguagem; Tecnológica; Ensino; Gênero discursivo.

\begin{abstract}
Analyzing memes and verbal and non-verbal language in the day-to-day of Portuguese language classes represents building some reflections for the appreciation and scope of the discursive materialities of memes within the school context. With the advent of the digital age, a lot of content is spread all the time, including memes. Therefore, several hypotheses arise and, among them, whether the verbal and non-verbal language within Portuguese language classes, through the analysis of memes, would promote learning in the Basic School. In view of the proposition, the fundamental objective of the study was outlined, which is to analyze the Languages axis and its codes through the appreciation of memes in the context of the day-to-day context of Portuguese language classes. It is intended, in an analytical case study, to read and select some texts, following the criteria: actuality, original and intelligent graphic proposal, social service and creatively approached. The corpora will be technologically disseminated texts for the description and explanation for a more active work in the school that at the moment lacks support for new proposals coming from paths beyond books and handouts. The basic theorists will be: Bronckart (2005); Kleiman (2007); Xavier (2002); Soares (2004) and BNCC (2016), among other authors. It is believed that verbal and non-verbal language within the context of daily life in Portuguese language classes can lead students to the perception of different semiosis proposed by the languages made possible by technology/WEB.
\end{abstract}

Keywords: Technological; Language; Teaching; Discursive gender.

\section{Resumen}

Analizar los memes y el lenguaje verbal y no verbal en el día a día de las clases de lengua portuguesa representa construir algunas reflexiones para la apreciación y alcance de las materialidades discursivas de los memes en el contexto escolar. Con el advenimiento de la era digital, se difunde mucho contenido todo el tiempo, incluidos los memes. Por tanto, surgen varias hipótesis y, entre ellas, si el lenguaje verbal y no verbal dentro de las clases de lengua portuguesa, a través del análisis de memes, promovería el aprendizaje en la Escuela Básica. A la vista de la propuesta, 
se planteó el objetivo fundamental del estudio, que es analizar el eje Idiomas y sus códigos a través de la apreciación de los memes en el contexto del día a día de las clases de lengua portuguesa. Se pretende, en un caso de estudio analítico, la lectura y selección de algunos textos, siguiendo los criterios: actualidad, propuesta gráfica original e inteligente, servicio social y abordado creativamente. Los corpus serán textos de divulgación tecnológica para la descripción y explicación para un trabajo más activo en la escuela que por el momento carece de soporte para nuevas propuestas provenientes de caminos más allá de libros y folletos. Los teóricos básicos serán: Bronckart (2005); Kleiman (2007); Xavier (2002); Soares (2004) y BNCC (2016), entre otros autores. Se cree que el lenguaje verbal y no verbal en el contexto de la vida diaria en las clases de lengua portuguesa puede llevar a los estudiantes a la percepción de diferentes semiosis propuestas por los lenguajes posibilitados por la tecnología / WEB.

Palabras clave: Idioma; Tecnológico; Enseñando; Género de discursos.

\section{Introdução}

A vida contemporânea tem imposto novos códigos que necessitam ser apreendidos para que o cidadão leitor possa se comunicar e estar apto para viver no mundo do trabalho e ver/sentir os novos textos como potenciais sinalizadores de uma nova era que se apresenta. Neste contexto, textos verbais e não verbais, como os memes, têm se destacado como importante metodologia na escola, com a finalidade de potencializar os estudantes para as propostas de leitura. Para tanto, a escola deverá privilegiar as linguagens e seus códigos para discussão entre os docentes no desígnio de potencializá-los para lidar com essas novas opções de ensino que são os textos sincréticos que fazem parte das elocuções tecnológicas. Como consequência desse novo contexto, será a oportunidade de fazer uma atmosfera favorável para a expansão e concretização do conhecimento dos estudantes.

Nesse novo espaço, os alunos começam a edificar suas primeiras impressões sobre letramento por meio de textos tecnológicos (multimodais e multisígnicos) e esses gêneros textuais encontrados no ambiente virtual são mais lúdicos e atrativos que os livros didáticos. Propostas em celulares, telas em geral que se situam em diferentes pontos da cidade provocam o despertar até mesmo do professor, além do interesse da comunidade acadêmica em pesquisar o tema. Surgem, portanto, várias hipóteses e, entre elas, se a linguagem verbal e não verbais usadas nas das aulas de língua portuguesa, por intermédio da apreciação de memes, promoveria a aprendizagem na Escola Básica.

Assim, pretende-se como objetivo, estudar o eixo Linguagens e seus códigos por meio da análise de memes no contexto do cotidiano das aulas de língua portuguesa, construindo algumas reflexões para apreciação e compreensão das materialidades discursivas dos memes dentro do contexto escolar com vistas a observar as práticas dos professores e propor alterações no ensino e adoção da tecnologia no cotidiano do ambiente escolar.

Devido ao aumento dos diversos fluxos linguísticos muito se evolui a fim de melhorar o ensino, compreendendo a reflexão que deve ser feita, no sentido de o educador e estudante estarem em atentos com tais descobertas. Percebe-se que essas linguagens passam a ser aferidos como gramáticas contextuais, em que se analisam a intencionalidade, a construção do gênero e os discursos presentes e isso constitui articular que tais linguagens compõem formas de letramento.

A proposta surgida dos memes foi discutida a partir do questionamento se a linguagem verbal e não verbal auxiliaria a consolidação da aprendizagem em sala de aula e seguida da investigação do fenômeno contemporâneo que são os memes, partindo de fontes primárias, do seu contexto real, utilizando-se de múltiplas fontes de evidências, com o apoio teórico de autores da Linguística e da linha teórica de leitura que são: Bronckart (2005); Kleiman (2007); Xavier (2002); Soares (2004) e a BNCC (2016), entre outros autores.

Dentro do Ensino Básico, o ensino fundamental é a segunda etapa da educação básica no Brasil e é nesse ambiente que o aluno começa a ser instigado e onde ele terá o livre-arbítrio de aventurar seus pensamentos através da escrita e leitura. Uma atmosfera perfeita para a ampliação e consolidação de seus conhecimentos.

Espera-se que com esse estudo, possa ser feita a verificação de como se dá a ampliação do conhecimento de forma crítica acerca do letramento virtual por intermédio de linguagens verbais e não verbais. Também se almeja constatar até que 
ponto a tecnologia pode ser parceira do professor na escola, no desenvolvimento de leitura, uma vez que sua participação na vida dos estudantes já é evidente.

\section{Metodologia}

O período tecnológico já está consolidado no nosso cotidiano, induzindo o sujeito ao uso desses recursos em diferentes atividades habituais, pois as capacidades digitais são condições básicas para estudar, trabalhar e relacionar. Essa conexão com as mídias digitais é ainda mais intensa nas gerações que nasceram nesse período, que não têm conhecimento ou prática em outra forma de conviver com situações e relações que não constitua com a mediação de aparelhos digitais. Deste modo, os alunos dessa contemporaneidade precisam aprender a usar tais instrumentos corretamente e concentrar o conteúdo ao qual estão aprendendo com o mundo digital.

Em busca do objetivo de estudar o eixo Linguagens e seus códigos por meio da análise de memes no cotidiano das aulas de língua portuguesa, efetivou-se a pesquisa para investigação do fenômeno contemporâneo que são os memes, partindo de fontes primárias, do seu contexto real. Almeja-se, em estudo de caso de natureza analítica, amparada por pesquisas bibliográficas, ler e selecionar alguns textos, seguindo os critérios: atualidade, proposta gráfica original e inteligente, conveniência social e a análise investida com inventividade.

Para atingir esta compreensão e desenvolvê-la, o estudo adotou em modelo de concepção de linguagem o interacionismo sociodiscursivo de Bronckart (2005), pelo crédito dado a interação que interlocutores podem fazer conjuntamente na tentativa de compreender as diversas dimensões dos indivíduos por meio da linguagem.

Os múltiplos tipos de gêneros virtuais podem beneficiar na aprendizagem dos estudantes de diferentes formas e em distintos contextos. Depende do formato que o educador irá inserir essa técnica nas suas aulas.

É importante que a instituição escolar preserve seu compromisso de estimular a reflexão e a análise aprofundada e contribua para o desenvolvimento, no estudante, de uma atitude crítica em relação ao conteúdo e à multiplicidade de ofertas midiáticas e digitais. Contudo, também é imprescindível que a escola compreenda e incorpore mais as novas linguagens e seus modos de funcionamento, desvendando possibilidades de comunicação (e também de manipulação), e que eduque para usos mais democráticos das tecnologias e para uma participação mais consciente na cultura digital (BNCC, 2016, p. 57).

A linha teórica foi dirigida por autores que conjeturam sobre leitura, como: Bronckart (2005); Kleiman (2007); Xavier (2002); Soares (2004) e a BNCC (2016), entre outros autores.

$\mathrm{O}$ corpo docente, muito mais agora exposto a atividades digitais, terá que estudar para ficar apto ao enfrentamento que ora vivencia e explorar a duplicidade analógica e tecnológica, buscando a maneira mais prazerosa e de conteúdos pertinentes aos discentes, conforme as séries e faixas etárias.

\section{Resultados e Discussão}

Ao inserir diversas leituras que fazem parte do dia-a-dia dos alunos, a escola deverá abrir espaço em suas reflexões para um ensino baseado em letramentos múltiplos que consigam alcançar os alunos e os capacitar para a criticidade necessária a uma cidadania de um modo protagonista.

A edificação da linguagem no aluno faz parte de seu progresso natural. Oferece-se como um trabalho sucessivo de preparação cognitiva por meio de inclusão no mundo da escrita pelas interações sociais e orais, avaliando a definição que a escrita tem na coletividade. Para Kleiman 2007, toda leitura está inserida em um contexto social e que poderá determinar as diferentes maneiras de escrever e de ler. 
Dentro da especificidade do conjunto da análise de memes no cotidiano das aulas de língua portuguesa, verifica-se que a técnica da leitura de linguagens verbais e não verbais tem um desígnio comunicativo, algumas vezes formal, outros informais. Vale ressaltar é que a prática deve atender às reais necessidades de acordo com cada ocorrência apresentada.

A coexistência dos estudantes com textos não verbais, mais designadamente os memes, é incontestavelmente um processo real e está presente no dia a dia deles e da comunidade escolar. É uma convivência que necessita de grandes cuidados e atenção, pois dependendo do conteúdo que o professor apresentar em sala de aula, os memes ajudarão os alunos a compreenderem o contexto histórico em que ele se apresenta, até mesmo poderão ser levados a um choque cultural, a um estranhamento.

É imprescindível uma proposta pedagógica que dê apoio ao íntegro desenvolvimento desses aspectos abrangidos na aprendizagem, tendo em vista adequarem aos alunos as formas de utilização da leitura e compreensão para diferentes intenções. Partindo-se de situações de letramento presentes em seu dia-a-dia, uma vez que os textos verbais e não verbais apresentam circunstâncias comunicativas diferenciadas, é possível o estudante compreender que a composição e a organização dos textos estão relacionadas a diferentes desempenhos que exercem nas práticas coloquiais da realidade. Conforme Soares (2004) "Alfabetizar e letrar são duas ações distintas, mas não inseparáveis, ao contrário, o ideal seria alfabetizar letrando, ou seja, ensinar a ler e a escrever no contexto das práticas sociais da leitura e da escrita".

A atuação adequada da linguagem torna-se um alicerce de direção para que os estudantes possam construir uma influência mútua com a sociedade, com as pessoas que vivem ao seu redor. A escolha correta do gênero textual a ser utilizado para o diálogo em determinados momentos é importante para que a comunicação seja de fato concretizada. Para isso, é imperativo que se tenha conhecimento dos gêneros textuais que existem que se saiba que eles também se transformam conforme o tempo passa, dependendo dos valores sociais do ambiente de onde se está e a necessidade do período que se vive.

...a produção verba real provém da escolha de um gênero textual que parece ser adaptado à situação, por meio de empréstimo ao arquitexto (em um processo de adaptação de um modelo textual), e pela exploração desse modelo, levando-se em conta as propriedades sempre particulares da situação de produção do actante (em um processo de adaptação desse modelo) (BRONCKART, 2005, p. 88).

O nível comum de uma escrita pode assumir formas bastante variadas, principalmente por duas razões. A primeira razão depende do gênero ao qual o texto pertence e a segunda está atrelada a fatores responsáveis pela singularidade dos textos trabalhados sendo fundamentada no conteúdo temático, dimensão do texto, tipos de apoio, variantes como oral-escrito ou dialógico-monológico.

É importante que a instituição escolar preserve seu compromisso de estimular a reflexão e a análise aprofundada e contribua para o desenvolvimento, no estudante, de uma atitude crítica em relação ao conteúdo e à multiplicidade de ofertas midiáticas e digitais. Contudo, também é imprescindível que a escola compreenda e incorpore mais as novas linguagens e seus modos de funcionamento, desvendando possibilidades de comunicação (e também de manipulação), e que eduque para usos mais democráticos das tecnologias e para uma participação mais consciente na cultura digital (BNCC, 2016, p. 57).

Para qualquer gênero ser movimentado é promovido do sujeito o domínio de determinadas capacidades de linguagem. Nesse sentido, permite ao sujeito agir com eficiência em situações de comunicação. Precisamos pensar na educação da linguagem tendo como desígnio principal a interação social em todos os âmbitos para que ela não se torne uma língua acabada, pronta, sem novas interpretações e interações. 
As condutas que regem os indivíduos são momentos que advêm de situações já vividas por eles, dentro dos diferentes contextos sociais e culturais. Cada vez mais ativados pelos instrumentos semióticos que brotam com o passar do tempo e defendidos pela corrente epistemológica denominada interacionismo social.

Percebe-se que, essas formulações conversam para a explicação e a definição dos seus relativos objetos de investigação, ou seja, de que a linguagem, a ampliação das funções superiores, assim como a constituição das crenças, parte do social até atingirem o individual.

Por este motivo o indivíduo possui suas formas de disposição e seus mais diferentes formatos de atividades. Mas são as atividades sociais ligadas ao uso da linguagem as mais enfocadas por essa abordagem.

O ponto de partida do sócio-interacionismo é a crença na historicidade do ser. Por essa razão, procura observar as condições em que formas de organização social foram desenvolvidas, e investigar os formatos interacionais e os instrumentos semiolinguísticas utilizados. Interessa ao sócio-interacionismo, portanto, compreender e descrever os processos filogenéticos e ontogenéticos que propiciam a aprendizagem de um dado sistema de linguagem capaz de viabilizar, com sucesso, as relações entre seres humanos que compartilham de um mesmo espaço social (Xavier, 2002, p 19).

No procedimento de aprendizagem de leitura, não basta apenas distinguir as letras e conectá-las, dando significado. Segundo Kleiman 2007, "muitos fatores envolvidos na dificuldade que um principiante encontra para chegar a ler é que os textos são muitas vezes difíceis para eles". O que faz da leitura muitas vezes complexa é a falta de compreensão do léxico e a ausência de conhecimento prévio do assunto o qual está lendo.

Entender o que se lê exige obter diferentes técnicas e fórmulas. Necessita-se ter esclarecimento do propósito da leitura, identificar aspectos importantes de uma mensagem, ter atenção aos conteúdos ministrados, fazer um monitoramento contínuo e verificar se os objetivos almejados estão sendo atingidos.

Na metodologia de leitura de memes verbais e não verbais deve-se analisar se os alunos se transformaram em leitores funcionais e autônomos, para que possam se instruir de forma significativa das estratégias responsáveis por uma leitura ativa e capaz de utilizá-las em múltiplos contextos históricos. Auxiliar os estudantes a situar o maior número de relações entre o que já conseguem e o que lhes é oferecido como novo colabora com a organização social da sala de aula aproveitando todas as possibilidades que ela oferece. Nessa perspectiva:

A função da escola, na área de linguagem, é introduzir a criança no mundo da escrita, explorando tanto a língua oral quanto a escrita como forma de interlocução, em que quem fala ou escreve é um sujeito que em determinado contexto social e histórico, em determinada situação pragmática, interage com um locutor, também um sujeito, e o faz levado por um objetivo, um desejo, uma necessidade de interação (Soares, 2002, p. 15).

Os estudos sobre mídias digitais voltadas para melhorias na aprendizagem devem estar em pleno desenvolvimento e se fazem necessárias no auxílio da construção do conhecimento. E essa inclusão entre educação e tecnologias, com o foco na socialização dos alunos com a aprendizagem, Kenski, 2012, p. 44, ressalta que "a presença de uma determinada tecnologia pode induzir profundas mudanças na maneira de organizar o ensino".

$\mathrm{O}$ aproveitamento de gêneros digitais nas aulas de língua portuguesa são ferramentas valiosas no processo de ensino e aprendizagem. $\mathrm{O}$ uso do meme permite a interação, atenuando a distância entre educadores e estudantes, dando vida a novos métodos de leitura e a escrita e na construção de textos verbais e não verbais com o uso do humor, da criação de animações, permitindo o acesso ao letramento.

Com efeito, o advento da Internet vem contribuir para a emergência de práticas sociais e eventos de letramento ainda não imaginados, bem como trazer ã tona gêneros textuais, até então, nunca vistos. Os recursos e dispositivos técnicos 
e informáticos hoje disponíveis na rede digital de comunicação possibilitam a fundação de formas sócio comunicativas inovadoras. Veja-se, por exemplo, que o Hipertexto, uma vez ancorado na tela do computador, faz nascer o modo de enunciação digital (Xavier, 2002, p 60).

Um dos papéis do ambiente escolar é desenvolver nos alunos a prática de uma convivência saudável na sociedade em que vivem. Desta forma, é imperativo que os alunos adquiram a aptidão da convivência digital, de usar e interpretar, apropriadamente, os recursos digitais, pois estes já fazem parte do convívio diário da coletividade.

[...] com raras exceções, os softwares educacionais são entendidos como um recurso auxiliar, pronto e acabado, que tem como funções reforçar conteúdos, motivar e avaliar conhecimentos. Em síntese, o software educativo tende a ser um canal ou veículo que transmite informações e administra tipos de exercícios aplicados tradicionalmente por um professor num quadro-negro ou por um livro didático (Santos, 2003, p. 40-41).

O uso das mídias digitais solicita a interação, favorecendo a participação dos estudantes nas atividades, pois os recursos que a tecnologia trás são muito eficientes em conservar as pessoas entretidas e focadas. Utilizar linguagens não verbais e verbais, como os memes, desperta o interesse dos estudantes em uma aula. Assim, eles se tornam mais engajados com o aprendizado e a obtenção do conhecimento se torna algo que será consolidado, pois acontecera, naturalmente. Uma das formas formidáveis do uso do letramento digital é a de estimular a criatividade dos seus usuários, já que o ambiente virtual é colaborativo e propicia a participação de todos. Participando das atividades digitais os alunos são provocados a usar a imaginação para resolver problemas lógicos.

O emprego das tecnologias para aquisição do letramento dos alunos admite que, primeiramente, é necessário letrar digitalmente os professores. Sendo assim, deve-se buscar o aperfeiçoamento desses profissionais para que possam oferecer aulas digitais com o uso das ferramentas disponíveis no ambiente online com qualidade e autonomia.

É necessário, sobretudo, que os professores se sintam confortáveis para utilizar esses novos auxiliares didáticos. Estar confortável significa conhecê-los, dominar os principais procedimentos técnicos para sua utilização, avaliá-los criticamente e criar novas possibilidades pedagógicas, partindo da integração desses meios com o processo de ensino (Kenski, 2004, p. 77).

Ministrar aulas online deixa a aula mais lúdica, criativa e divertida de ensinar. Os conteúdos que estão na grade curricular daquele ano se colocam em prática e as competências digitais aprendidas são familiarizadas com os recursos tecnológicos que os estudantes trazem de suas experiências com a internet. Ainda assim é adequado pontuar que o contato com as TICs deve ser habitual porque a tecnologia é dinâmica e evolutiva, o que faz com que suas ferramentas e aplicativos se reconstruam rapidamente, exigindo continuamente novas aprendizagens.

Atualmente, estudantes e educadores têm contato diário com a internet, dentro e fora da escola. Diversos alunos aprendem a usar os celulares, computadores e tablets mesmo antes de irem para a escola.

Desta forma, quando se reflete sobre letramento digital que possa se consolidar no dia a dia dos estudantes e educadores é preciso que as escolas ofereçam infraestrutura e equipamentos que sigam o desenvolvimento tecnológico. Não é só a sala de informática que irá promover esse letramento virtual, mas também desenvolver salas multimídia, equipamentos móveis para serem usados em sala de aula, internet para uso nas atividades digitais, para que professores e alunos possam acessar vídeos e outros conteúdos interativos no momento das aulas e capacitação frequente dos professores.

As tecnologias garantem às escolas a possibilidade de se abrir e oferecer educação para todos, indistintamente (...). $\mathrm{O}$ uso intensivo das mais novas tecnologias digitais e das redes transforma as dimensões da educação e dá à escola 'o tamanho do mundo' (Kenski, 2007, p. 124). 
Um dos grandes recursos que o educador utiliza para colaborar com a aprendizagem dos estudantes é contar histórias, de histórias orais até a leitura de livros, objeto básico para o letramento habitual. Atualmente, no momento tecnológico, chegou à vez das narrativas digitais receberem sua vez dentro do letramento. Abordar textos verbais e não verbais publicados na internet, tendo recursos ou não de áudio e vídeo, transformam o conhecimento em algo divertido e chama a atenção dos estudantes.

Atualmente, com o vasto conteúdo que se absorve vindos das tecnologias, diminui-se o tempo em que se consegue ficar focado em alguma coisa. Desta forma, a narrativa digital é um recurso competente para transmitir conhecimentos porque consegue apresentar, de 5 a 10 minutos o que o educador levaria a aula inteira para explicar.

A aptidão de interação, que é uma das maiores bases da tecnologia, pode ser aproveitada em conjuntos de aprendizagem na sala de aula, como os letramentos de textos verbais e não verbais retirados dos memes.

A linguagem digital, expressa em múltiplas TICs, impõe mudanças radicais nas formas de acesso à informação, à cultura e ao entretenimento. O poder da linguagem digital, baseado no acesso a computadores e todos os seus periféricos, à internet, aos jogos eletrônicos etc., com todas as possibilidades de convergência e sinergia entre as mais variadas aplicações dessas mídias, influencia cada vez mais a constituição de conhecimentos, valores e atitudes. Cria uma nova cultura e outra realidade informacional (Kenski, 2008, p. 33).

$\mathrm{O}$ ambiente escolar de hoje deve privilegiar as diversidades de linguagens como a compreensão da linguagem informal, verbal e não verbal diante de seus múltiplos contextos, a referência de discursos, ideias, construções de significados, suas contribuições culturais, o espaço para as novas tecnologias, metodológicas e constitucionais.

Ao inserir todas essas todas essas linguagens, privilegia-se uma educação baseada em letramentos múltiplos que conseguem alcançar os alunos e os capacitam em operar na cidadania de um modo protagonista.

Este é um gênero emergente que poderia ser bastante explorado na e pela escola. Os professores de língua portuguesa poderiam utilizar este gênero digital para dinamizar suas aulas de produção textual. A mudança de ambiente, da sala de aula para o laboratório de informática, e a descoberta das características e potencialidades de desenvolvimento retórico-argumentativo poderia tornar a aula de português mais empolgante e atraente. (Xavier \& Santos, 2005, p. 37).

Conservar os alunos concentrados é um grande desafio para o docente, pois estão habituados com a aceleração que a tecnologia desempenha. Sendo assim, as escolas devem adotar metodologias para instigar a curiosidade dos alunos e conservar o interesse em aprender e interagir. Além disso, devem investir na formação continuada dos de docentes para melhor qualificação no mundo virtual.

Ao utilizar as metodologias ativas, que proporcionam ao aluno ser peça fundamental da sua aprendizagem, o educador se transforma em intercessor dessa aprendizagem dentro no ambiente escolar. Ao desenvolver conteúdos curriculares que provocam os estudantes a resolverem dificuldades de forma criativa, o docente se transforma em mediador dos conteúdos que devem ser aprendidos.

Os docentes carecem de formação continuada, necessitam atuar no mundo digital com facilidade e rapidez, pois em um mundo em que o acesso à informação é cada vez mais veloz, diferentes habilidades devem ser estabelecidas no mundo escolar. O docente não é o possuidor do saber e investir em exercícios sobre as novas diretrizes da educação e inovações nas metodologias de ensino digital é essencial para que se conectem com as novidades nos métodos de aprendizagem digital. De acordo com Freire 2001, ensinar inexiste sem aprender e vice-versall.

Uma metodologia de ensino que estimula o aluno a refletir "fora da caixa" é essencial para formar indivíduos conscientes e preocupados com a coletividade. Segundo Perrenoud 1999, a prática pedagógica depende de toda equipe 
envolvida, em um trabalho coletivo, buscando diversas estratégias consideradas necessárias para o desempenho do exercício da educação, criando o que denomina 'revolução de competências',

A principal reflexão proposta é o emprego do gênero textual meme verbal e não verbal dentro de um contexto de análise de memes no cotidiano das aulas de língua portuguesa $\mathrm{O}$ momento é de inclusão digital, onde o uso de recursos tecnológicos nas interações sociais se faz cada vez mais atual, os alunos dispõem de múltiplos meios para comunicar-se com os demais e isso possibilita momentos de absorção e compartilhamento de informações dentro e fora do ambiente escolar.

Neste contexto os professores da educação básica deverão se adaptar a esse ambiente tecnológico e se adequar aos novos recursos midiáticos com o objetivo de introduzi-los em sugestões pedagógicas que tornem o processo de ensinoaprendizagem mais expressivo para os alunos. Os memes, que comumente são capturados em momentos de deboche, podem ser aliados que amparam o professor na aproximação da sua aula com o mundo tecnológico em que estamos inseridos.

O uso dos memes dentro dos conteúdos da grade curricular da escola pode permitir que as interconexões dos alunos fossem inseridas no contexto escolar, tornando a aula mais conectada com as novas configurações de comunicação. Dentro do aspecto de construção de uma sala de aula mais eficaz e conectada com o dia-a-dia e as interações sociais dos alunos, o uso de memes verbais e não verbais estimula a construção do conhecimento de forma mais efetiva. Para que um meme possa envolver e passar uma determinada mensagem é preciso que esteja embasado em leituras dos conteúdos vistos na aula.

\section{Leituras do cotidiano: os memes como propostas}

Acompanham algumas imagens como exemplo de como podemos usar os memes nas aulas para aprimorar o aprendizado dos estudantes e tornar a aula mais divertida e interessante.

Figura 1 - Meme sobre inclusão digital.

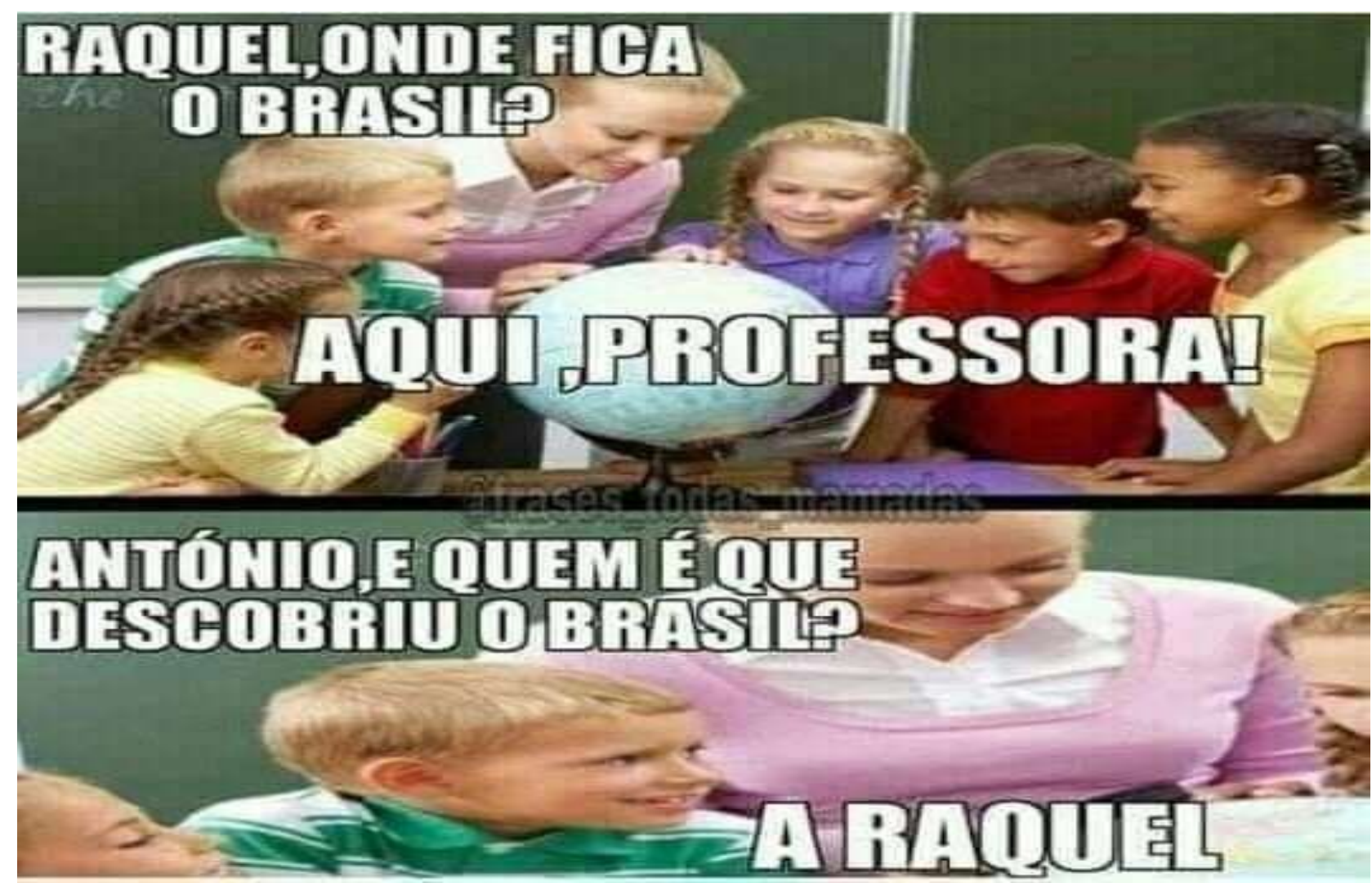

"Fonte: https://br.pinterest.com/pin/835417799614504287/" 
Na Figura 1, observa-se que a professora está introduzindo o conhecimento geográfico para os alunos, pois na linguagem não verbal observamos o globo. E no discurso verbal, dentro de um contexto histórico, percebe-se que ela entra também na aula de História, indagando sobre o descobrimento do Brasil.

De uma forma divertida, os alunos entrarão no conteúdo com a real curiosidade de saber quem de fato descobriu. A resposta do menino, no entanto, está em espelho à questão do descobrimento do Brasil muito discutida pelos portugueses e historiadores.

A fotografia mostra "António" com acento agudo exatamente como é a grafia do português de Portugal. Observação que aponta para o incômodo que o descobrimento do Brasil pode causar na história de Portugal, quando é dito que outros países já haviam passado por aqui. Obviamente que nenhum país gostaria de por em dúvida suas conquistas.

Assim, o meme é irônico, no viés da análise do discurso histórico. A figura de linguagem ironia representa dizer-se o contrário do que se quer dar a entender. É o uso de palavra ou frase de sentido diverso ou oposto ao que deveria ser expresso para definir ou denominar algo, com a finalidade de dar ênfase ao contexto.

O momento da sala de aula serviu para o tom humorístico, mas a polifonia leva o leitor a pensar também a situação histórica - ironia como argumentação elaborada pelo autor do meme.

Figura 2 - Meme sobre o Iluminismo.

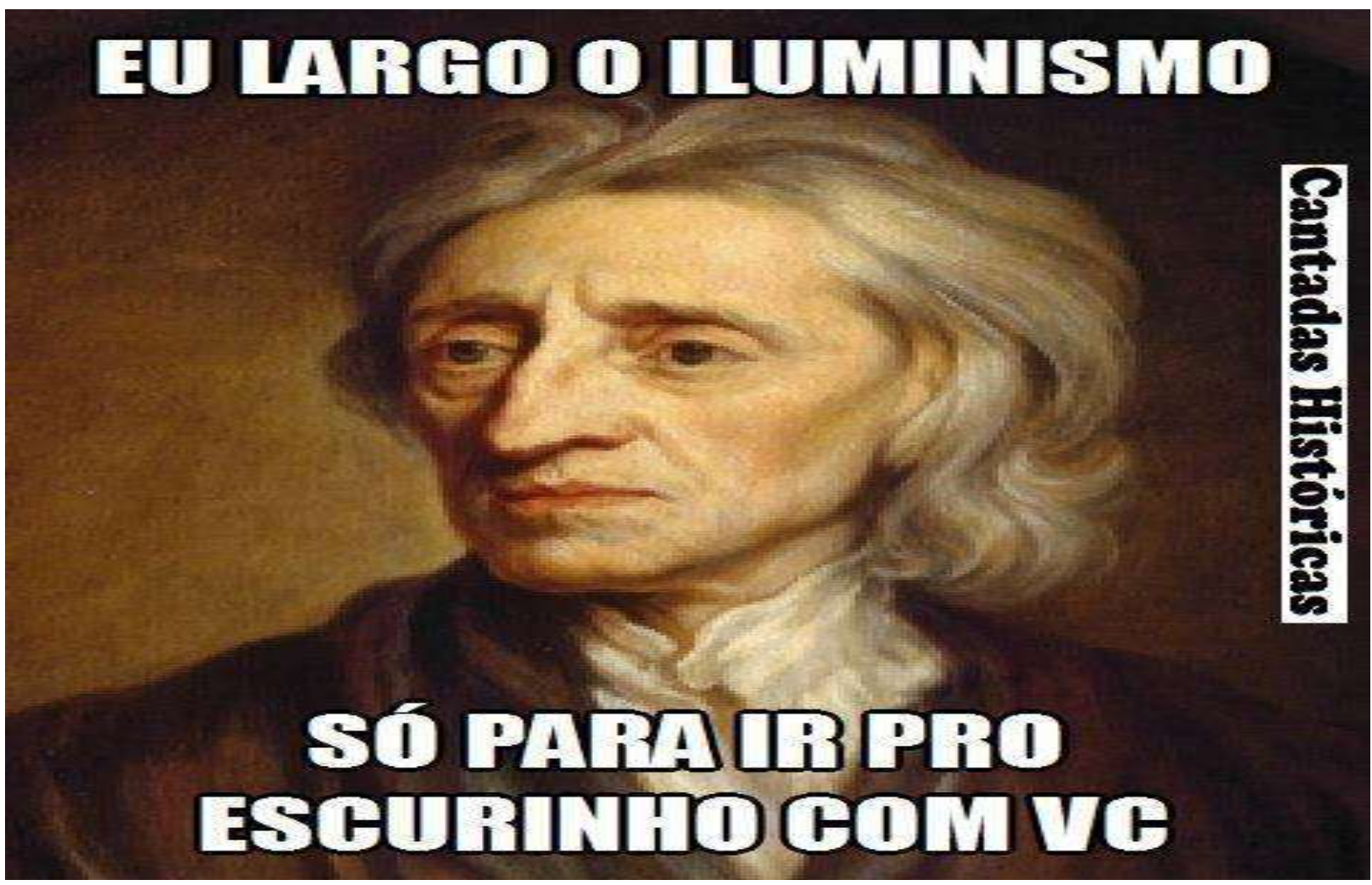

"Fonte: https://br.pinterest.com/pin/709668853764574329/"

Nas aulas sobre os movimentos intelectuais e filosóficos que dominaram o mundo das ideias na Europa durante o século XVIII, a atualidade dos memes pode ser um recurso atraente, dando suporte didático, permitindo inovações a respeito dos fatos históricos, conforme a Figura 2 sobre o Iluminismo. 
O meme em questão abre espaço para uma discussão sobre o que foi o iluminismo e sua importância na história mundial. Com uma apresentação em formato de meme, faz com o assunto se torne mais leve, e pode-se obter a atenção dos alunos nas aulas.

Da forma como o meme foi apresentado, sua forma verbal informa, ainda que de maneira informal, que o iluminismo era algo bom, uma noção otimista do mundo. E como se pode perceber isso? Quando ele informa que largaria o iluminismo "para ir para o escurinho com você".

Essa figura de linguagem, que consiste na exposição de ideias opostas, desperta nos alunos a curiosidade, a vontade de conhecer mais sobre o assunto e pode ajudar a levantar pistas que podem subsidiar a compreensão.

A variedade de formas de como um conteúdo pode ser apresentado auxilia os alunos na conexão com a disciplina e faz a aula mais atraente e consolida os conteúdos de forma concreta.

Figura 3 - Meme sobre as aulas de história.

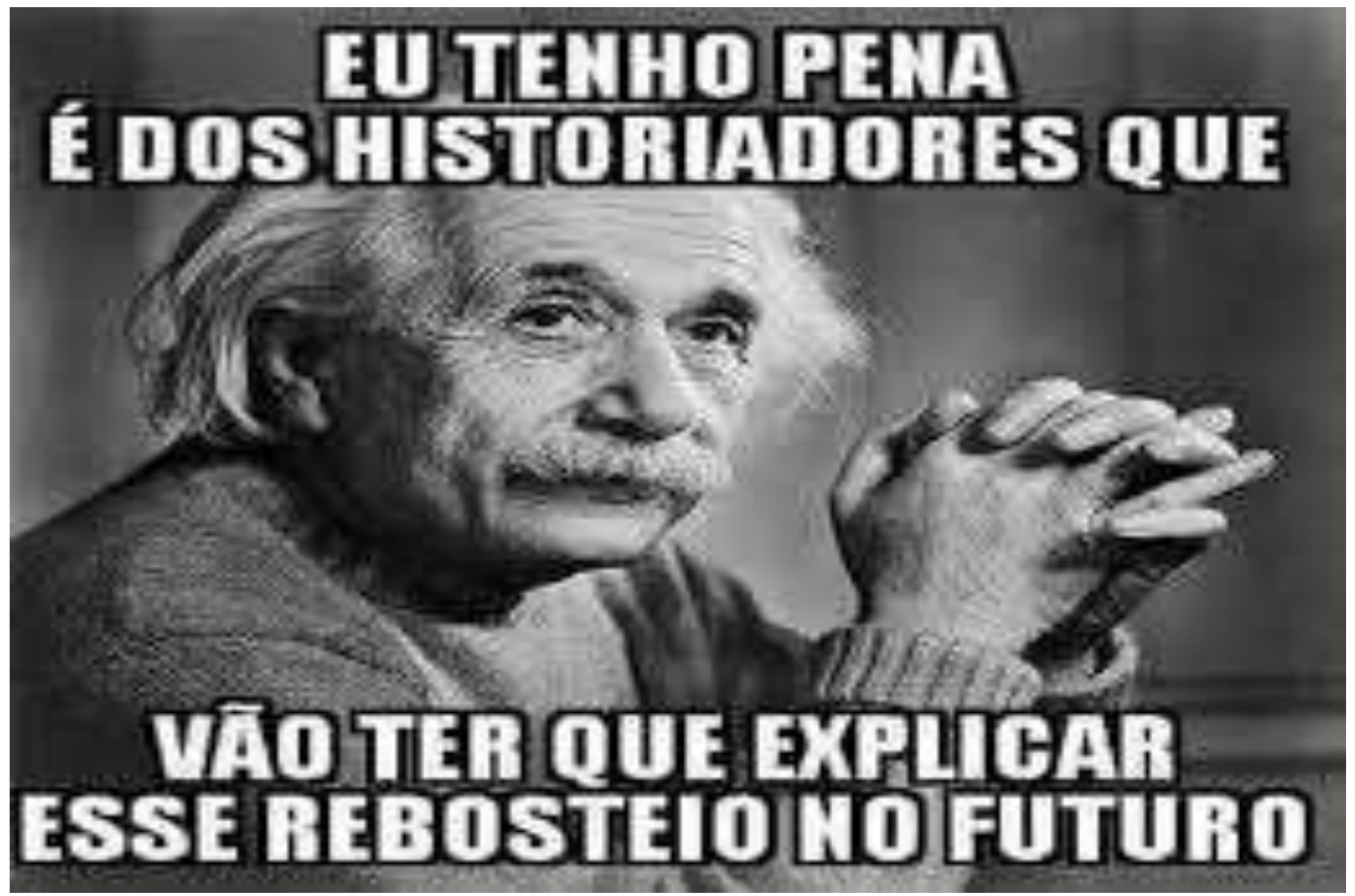

"Fonte: https://www.facebook.com/cursovazafalsiane/posts/19-de-agosto-dia-do-historiador/908229199560561/"

Em semelhança à estrutura dos memes, percebe-se que, eles são estruturados por meio de uma correlação lógica e intencional de conceitos que permitem persuadir e arquitetar um conceito estruturada sobre fatos sociais.

A terceira Figura é sobre as aulas de história, sobre como será difícil explicar tudo que estamos vivendo atualmente. Sobre como os acontecimentos estão ocorrendo de forma rápida e, por muitas vezes, incoerentes.

O uso do meme na edificação do conhecimento excita novas abordagens pedagógicas e gera questionamentos que permitem aos alunos terem autonomia na construção de suas próprias leituras de mundo e socialização de ideias.

Os memes não são apenas uma forma de entreter-se sobre os fatos sociais. Os elementos que transportam e as ideias que passam para o público que os leem podem fornecer indicações sobre os códigos conceptuais em jogo. 
A contradição que aparece no meme da imagem 3 pode ser analisada primeiramente por simplesmente ser considerada engraçada. E é nesse sentido que o meme funciona. Ele prende a atenção do leitor e o leva a querer entender o porquê do duplo sentido. Eesse é recurso expressivo pois as palavras e expressões utilizadas possuem diferentes interpretações. Exemplo disso é a palavra rebosteio, que no meme significa um encadeamento de acontecimentos negativos ou de intervenções mal sucedidas, mas etimologicamente esta palavra deriva de bosta, excremento animal, de odor e aspecto desagradáveis.

\section{Conclusão}

A consideração de multiletramento e de técnicas da mídia digital contribui para uma participação mais concreta e crítica nas práticas atuais de linguagem dos alunos, tendo em vista que com esses aprendizados eles possam fazer mais do que usufruir do uso da linguagem - para que os estudantes consigam também modificar o que já construíram e passarem a descontruir (se necessário) os conhecimentos que já solidificaram, produzindo assim novos sentidos e novos entendimentos para seus questionamentos e desígnios.

Mudaram os tempos e a conjuntura escolar exige que saber agregar as tecnologias de uma forma inovadora se torna essencial. Às vezes a presença de textos tecnológicos não quer dizer que fundamentalmente serão usados de forma inovadora, precisando assim serem ampliadas metodologias para que os docentes possam fazer do uso desses gêneros virtuais algo benéfico e inovador.

As probabilidades em seu uso são ilimitadas e podem ser usadas em qualquer disciplina, principalmente nas aulas de língua portuguesa, onde a compressão abstrata é imperativa para se chegar a uma eficaz aprendizagem.

O bom emprego de gêneros digitais - principalmente dos memes - em sala de aula são instrumentos preciosos no processo de ensino e aprendizagem da leitura, porque permitem o multiletramentos, além de consentir o contato com as situações do dia-a-dia, favorecedoras de distintas vivências: o ódio, a ironia, a esperança, entre tantas emoções que animal o homem moderno.

É de suma importância que o docente perceba que ele pode ser um mediador desse despertar dos alunos para uma aprendizagem mediada pelo uso de memes na linguagem verbal e não verbal em um contexto dentro do cotidiano das aulas de língua portuguesa e que talvez ele possa ser uma ponte que leve os alunos com segurança e beleza ao incrível mundo do conhecimento por meio das mídias digitais.

Toda a comunidade escolar deve estar atenta ao momento contemporâneo de seus estudantes e verificar que precisa estar em pleno desenvolvimento virtual para assegurar esse processo de evolução digital que está presente no cotidiano. Os estudos voltados para era digital devem estar em desenvolvimento e se fazem necessários para auxiliar a construção do conhecimento de professores e alunos.

Estamos continuamente passando por transformações e elas estão acontecendo em um ritmo cada vez mais acelerado. Neste sentido, precisamos acompanhar essas mudanças para que a escola e professores estejam à frente de seu tempo. Acreditamos que futuramente nosso estudo esteja voltado para o trabalho com recurso digital em escolas que atendam alunos com necessidades especiais. E concluindo esse trabalho, estaremos construindo mais um artigo na busca incessante por informações e atualizações na área de alfabetização digital.

\section{Referências}

Brasil. (2016). Ministério da Educação. Base nacional comum curricular. MEC. http://basenacionalcomum.mec.gov.br/.

Bronckart, J. P. (2005). Atividade de linguagem, textos e discursos: por um interacionismo sociodiscursivo. EDUC. 
Research, Society and Development, v. 10, n. 11, e175101119523, 2021

(CC BY 4.0) | ISSN 2525-3409 | DOI: htttp://dx.doi.org/10.33448/rsd-v10i11.19523

Chauí, M. (1997). Convite à Filosofia. Ática.

Ferreiro, E. \& Teberosky, A. (1999). Psicogênese da língua escrita. Artmed.

Freire, P. (2001). Pedagogia da Autonomia: saberes necessários à prática educativa. Paz e Terra.

Gil, A. C. (2010). Como elaborar projetos de pesquisa. Atlas.

Jesus, D. M. (2004). O desafio de ser Professor em ambiente digital de aprendizagem: Um Olhar Crítico. Abril.

Kenski, V. M. (2008). Educação e tecnologias: O novo ritmo da informação. Papirus.

Kleiman, A. B. (2007). Letramento e suas implicações para o ensino de língua materna. Signo.

Kleiman, A. B. (1995). Os significados do Letramento. Uma nova perspectiva sobre a prática social da escrita. Mercado de Letras.

Koch, I. G. V.(2009). Desvendando os segredos do texto. Cortez.

Koche, J. C. (2011). Fundamentos de metodologia científica. Vozes.

Lara, M. T. A. \& Mendonça, M. C. (2020). Bakhtiniana: Revista de Estudos do Discurso. O meme em material didático: considerações sobre ensino/aprendizagem de gêneros do discurso, 15 (2), 185-209. 10.1590/2176-457335352.

Ludke, M. \& Andre, M. E. D. A. (2013). Pesquisas em educação: uma abordagem qualitativa. E.P.U.

Novoa, A. (2002). Formação de professores e trabalho pedagógico. Educa.

Perrenoud, P. (2002). A prática reflexiva no ofício de professor: profissionalização e razão pedagógica. Artmed.

Santaella, L. (2020). Revista de Computação e Tecnologia da PUC. A aprendizagem ubíqua substitui a aprendizagem formal? 03 (1), 17-22. https://revistas.pucsp.br/.

Santaella. L. (2004). Comunicação e semiótica. Hacker.

Soares, M. (2004). Revista Pátio. Alfabetização e Letramento, Caminhos e Descaminhos, 29 (8), 20. https://www.educabrasil.com.br/revista-patio.

Soares, M. (2008). Alfabetização e Letramento. Contexto.

Tfouni, L. V. (2006). Letramento e alfabetização. Cortez.

Vigotski, L. S. (2008). Pensamento e linguagem. Martins Fontes.

Yin, R. K. (2015). O estudo de caso. Bookman. 